\title{
Deconstructing collective building in social insects: implications for ecological adaptation and evolution
}

\author{
E. Invernizzi ${ }^{1}(1)$. G. D. Ruxton ${ }^{1}$
}

Received: 20 December 2018 / Revised: 22 July 2019 / Accepted: 31 July 2019 / Published online: 8 August 2019

(c) The Author(s) 2019

\begin{abstract}
Nests built by eusocial insect species are often complex structures consisting of multiple effectively integrated and functionally distinct substructures. Stigmergy, self-assembly and self-organisation have been proposed as the mechanisms that translate simple individual behaviour into coordinated collective activity. Here, we consider these processes focusing on their implications for the generation of new structures, nest adaptiveness and the evolution of building rules. We discuss in particular how self-organisation and stigmergy may guide the shift between substructures during building and generate new elements, either as an indirect result of building rule sets evolved for other purposes and under direct selection. The same mechanisms generate local, short-term adaptation through exploration of the phenotype space of the construction. Finally, we introduce the hypothesis that feedback dynamics create evolutionary transition between collective level phenotypes when mutations arise in the worker line, thus facilitating colony survival and affecting the evolution of collective building rules and of nest shape. This smooth transition is possible only when the new and the old rule variant are compatible. We call for new research that investigates self-organisation in collective building from an evolutionary perspective.
\end{abstract}

Keywords Nest building $\cdot$ Collective building $\cdot$ Collective behaviour $\cdot$ Self-organisation $\cdot$ Evolution $\cdot$ Eusocial insects

\section{Architectures of social and eusocial insects: complexity in the detail}

The architectures built by insect collectives display a variety of forms. Here, we focus on two features that are common to all and that underlie the functionality and adaptiveness of these structures. The first one is functional organisation, where the nests of these species are organised into functionally distinct elements. The nest of leaf-cutting ants, for example, consists of a network of major tunnels leading deep into the soil (Acromyrmex sp) from which nest chambers housing the brood and fungus branch out, connected through a short peduncle (Atta sp and Acromyrmex sp). Despite inter-specific variety (Moreira et al. 2004a, b; Verza et al. 2007; Bollazzi et al. 2012), this essential form of structural organisation is ubiquitous in the genus (Tschinkel 2015). Similarly, ant nests across ant species share the same layout of one or more shafts laterally connected to chambers,

E. Invernizzi

ei21@st-andrews.ac.uk

1 Sir Harold Mitchell Building, School of Biology, University of St Andrews, St Andrews KY16 9TH, UK with the number and angle of shafts, frequency and shape of chamber and relative distance between elements being defining species-specific features (Tschinkel 2015). In Atta species, there is also evident fine-tuned functionality of specific structural elements: nest ventilation is passively driven by surface wind through two distinct tunnel types, a central tunnel, for outflow, and several peripheral ones found at a lower level, for inflow (Kleineidam et al. 2001). The same type of structural organisation and the exploitation of similar environmental forces for thermoregulation and gas exchange are also observed in termites (Bonabeau et al. 1998; Korb and Linsenmair 1998; Ocko et al. 2017). A different type of complex structure is found in social wasps and bees, where nests consist of geometrically arranged cells creating a nest structure with species- or genus-specific characteristics. These structures also are likely to have thermoregulatory properties (e.g., Höcherl et al. 2016). In wasp species living in larger groups, the final nest is often composed of repeated submodules built in sequence and linked through connecting structures (Starr 1991; Fig. 1).

Second, beside finely developed functionality and structure subdivision and specialisation, a key feature of many eusocial insect nest architectures is flexibility, which allows 


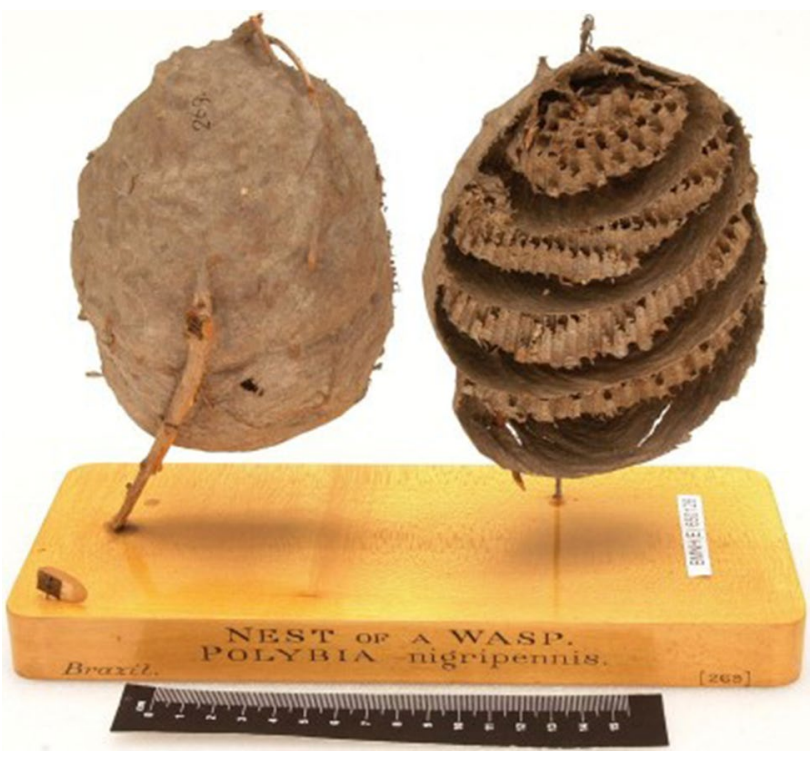

Fig. 1 Nest of the social wasp Polybia nigripennis, with cross-section. The inside of the nest consists of connected repeated modular structures. (C) The Trustees of the Natural History Museum, London

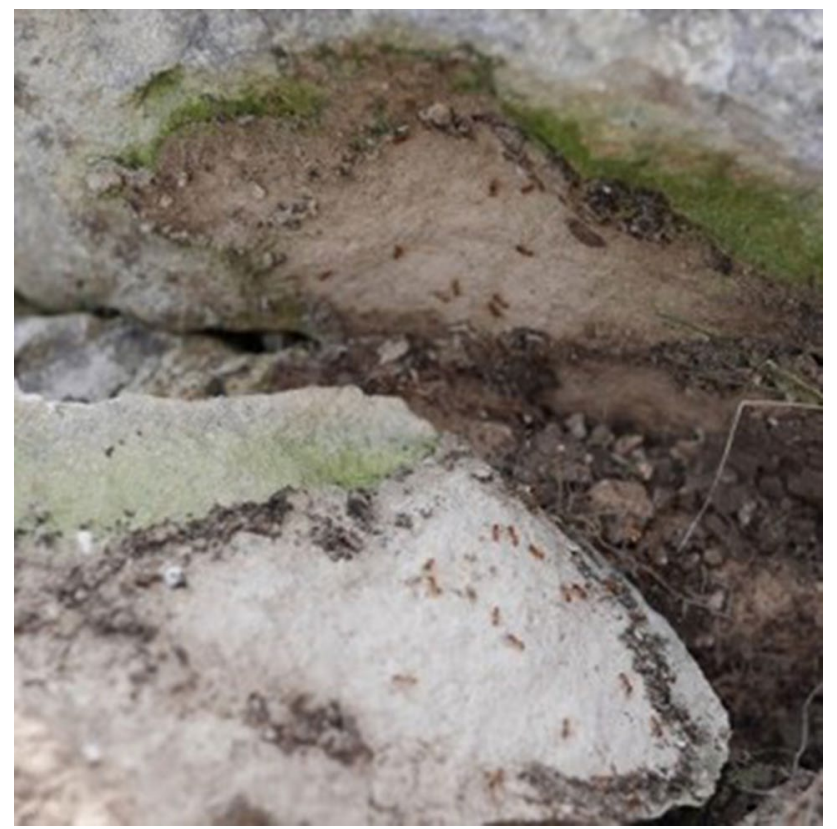

Fig. 2 Exposed Temnothorax albipennis nest. The wall is centred around the cluster of queen, brood and nursing ants. Image courtesy of T. Sasaki

adaptation to both the local environment and to changing functional needs of the colony. In the crevice-dwelling ant Temnothorax albipennis, builders accumulate material (dirt granules) at a distance from the queen, brood and nursing ants that is proportional to colony size at building, creating a circular nest wall around the colony (Fig. 2). If after construction the colony expands in number above a certain threshold, the existing wall is dismantled and a new one built at a longer radius (Franks et al. 1992). A similar phenomenon occurs for the royal chamber of Macrotermes (Bruinsma, 1979; Grassé, 1939). In leaf-cutter ants, again, the number of nest openings changes in response to external and internal humidity and temperature levels and airflow, to provide nest homeostasis (Bollazzi and Roces 2007, 2010a, b).

Below we review the mechanisms proposed to underlie nest construction, in the light of the flexibility and functionality they provide to the nest.

\section{Mechanisms of building}

\section{Main hypotheses}

The simplest proposed mechanism underlying complex building (Camazine et al. 2001) is the use of a series of actions in a fixed temporal or spatial sequence, a recipe. There is evidence of animals using a fixed sequence of building actions at some or all stages of construction, found in spider web and moth cocoon weaving (Foelix 2011; e.g., Lounibos 1975), but also in the linear phase of nest building in the primitively eusocial wasps Polistes fuscatus (Downing and Jeanne, 1988). A drawback of building strategies relying entirely on fixed progression is, however, the lack of flexibility in responding to unusual circumstances: the classic example is that of solitary potter wasps Paralastor sp., that are shown to respond to an artificially induced hole resembling one of the construction stages in their nest by replicating the construction sequence from that point onwards, even if this leads to an aberrant structure (Smith 1978).

A second drawback of the recipe mechanism is that building is isolated from the assessment of external factors (this limitation is shared by what has historically been another of the proposed mechanisms underlying complex building, the use of a blueprint, i.e., a fully explicit description of the target structure to be built; Thorpe 1963). From the point of view of structure functionality, it follows that builders using this mechanism cannot take local environmental features into account and also cannot react flexibly to the environmental factors the structure exploits. This is in contrast with what was observed for example, in Macrotermitinae and in leaf-cutter ant workers, whose activity relies on the continuous assessment of air currents, temperature and humidity gradients (Harris 1956; Roces and Kleineidam 2000; Kleineidam et al. 2001; Turner 2000, 2001; Bollazzi and Roces 2007, 2010a, b; Bollazzi et al. 2012; King et al. 2015). Insensitivity to local cues is likely problematic especially in species whose habitat range covers quite a wide spectrum of relevant environmental conditions, where seeking to replicate a fixed blueprint or recipe might put the colony at risk 
of maladaptation. In leaf-cutter ants, in particular, workers have been shown to open and seal nest outlets to the surface selectively, in response to dry but not humid and incoming but not outgoing currents flowing through (Bollazzi and Roces 2007, 2010a). The number of outlets increases with decreasing external humidity and increasing external temperature, hereby modulating nest humidity and temperature (Bollazzi and Roces 2010b). Inter-colony variation has been studied and found in Temnothorax rugatulus ants, where $5-20 \%$ of this variation is explained by differing environmental conditions (DiRienzo and Dornhaus 2017). Large intraspecific variation in nest structure is well documented in Macrotermitinae (Coaton \& Sheasby, 1972; Darlington, 1984; Grassé \& Noirot, 1961; Harris, 1956; Pomeroy, 1977) and in leaf-cutting ants (Moreira et al. 2004a, b; Verza et al. 2007; Bollazzi et al. 2012; Tschinkel 2015) and evidence of structure adaptation that matches macroscopic environmental conditions exists at least in some insect species. Macrotermes bellicosus mounds found in forests have a domelike structure and reduced external ridges, providing reduced ventilation but increased thermal homeostatic capacity compared to the ridged pinnacle mounds built in open savannah (Korb and Linsenmair 1998). The leaf-cutting ant Atta vollenweideri controls structural stability and wall porosity when presented with different building materials by combining substrates with different physical properties at different ratios (Cosarinsky and Roces 2012). From the point of view of collective behaviour, moreover, recipes (or blueprints) cannot guarantee coordination of the independent activity of thousands of individuals: even when considering sensory feedback from neighbouring worker activity, different worker groups might develop the structure at the same time in different directions and the same structure can be built multiple times by workers tending to distant sections-especially in large structures. Coordination of large, complex structures using a blueprint would require a degree of labour division within building activity not documented so far in any social insect.

The use of rules exploiting templates-reference points from which to measure the distance and shape of deposition of the building material-allows building with respect to environmental elements, other features in the same construction or even focal individuals (Theraulaz et al. 1998). Template-based building enables both the incorporation of cues with adaptive value and of cues on the geometry of the structure. Structure size, shape and position can be adaptively fit this way. In Polistes fuscatus, for example, the position on the pedicel where construction of the first nest layer starts is carefully evaluated as a function of distance from the substrate, as proximity to the tree is crucial for nest access by predating ants (Downing and Jeanne 1988). Workers of the Formosan subterranean termite orientate the excavation of new galleries through reference vectors from the tunnel of origin (Bardunias and $\mathrm{Su}$ 2009a). Possibly more importantly, templates also allow directly guided, flexible, immediate adaptation of the architecture to functional needs. An example occurs again in Macrotermes, where workers deposit building material in relation to distance to the queen's ever-expanding and contracting belly and modify chamber size accordingly throughout the life span of the colony (Grassé 1939; Bruinsma 1979). Direct feedback of this type between function and structure construction, however, does not provide information on any elements other than the template, that is, each builder's knowledge is local and not global. This might be an important limitation. For example, in Temnothorax albipennis, nest walls (Fig. 1b) need to suit the size of the brood cluster, but also that of the colony population size. While there is evidence that wall construction, similarly to Macrotermes, occurs in relation to distance to the brood, use of a physical template alone cannot explain rebuilding in response to colony size expansion. In this sense, a non-obvious type of spatial or temporal template is that of the builder's activity itself in terms of spatial or temporal units elapsed, since a particular action was performed, or of templates informative of nest mate density, such as chemical templates or the mechanical template generated by impact with other workers (Camazine et al. 2001). Ant nests are known to grow proportionally to colony size (Tschinkel 2015; Perna and Theraulaz 2017).

Physical structures, activity-based reference points, volatile elements such as chemicals and environmental factors have all been shown to act as templates. Queen-released pheromone in termites is the most well-studied case (Bonabeau et al. 1998; Camazine et al. 2001), while instances of humidity, light and temperature gradients, as well as air currents (Sudd 1972; Tohmé 1972; Ceusters 1986; Roces and Kleineidam 2000; Kleineidam et al. 2001; Bollazzi and Roces 2007, 2010a, b; Jost et al. 2007; Ocko et al. 2017) have also been identified. Template mechanisms based on environmental conditions or features can directly feedback on the suitability of the structure to local space and guide its shaping, explaining how local factors can be taken into account in detail. For example, temperaturedriven removal and deposition of soil in Macrotermes have been proposed as a driver of mound shape adjustment to sun exposure (Turner 2000). The nest structures of termites and leaf-cutting ants cited above, in particular, rely on environmental conditions for their functions. Gas exchange, for example, occurs through ventilation generated by tunnels on the basis of daily temperature oscillations, in Odontotermes obesus (King et al. 2015), such that the underlying building mechanism needs to be tightly linked to local condition sensing. 


\section{Collective building}

Collective building shows two apparently contradicting features. First, despite the emerging structure being coherent, individual behavioural events appear random to some extent (Camazine et al. 2001). These instances of stochastic behaviour are a consequence of probabilistic, rather than deterministic, building rules in the use of templates. Second, the coherence of the final structure implies a degree of behavioural coordination that cannot be achieved by the use, alone, of the building mechanisms proposed above. Actions from a fixed spatial or temporal sequence performed by multiple individuals will clash and result in an unstructured architecture unless division of labour is extremely fine. The use of templates does guide individuals to construct the same architecture. However, a complex structure includes a high number of features, which would in turn require a large number of templates and of rules guiding the shift between templates. The cognitive capacity for such a high number of rules is expected to be large. The minimisation of both the amount of high-level organisation required and the number of rules a worker needs for a complex structure can be achieved with the help of three mechanisms: stigmergy, self-assembly and self-organisation (Theraulaz et al. 1998; Camazine et al. 2001; Theraulaz et al. 2003; Sumpter 2010).

\section{Stigmergy}

Stigmergy (Grassé 1959) can be summarised as the recognition and consequent response to selected (stimulating) spatial configurations found in the environment or arising as intermediate stages in the building process. Such response manifests in a change in the quantitative (in intensity of) or qualitative (in the form of) type of building activity and is stimulus specific, so that different stimulating configurations produce different responses. This type of building rule is similar to recipes in that they recognise previous structures and respond with pre-established actions, but have, in contrast, the advantage of being unbound to a temporal or spatial sequence. As long as individuals do not discriminate between building done by themselves and others, they can collectively contribute to the same structure by applying the same set of rules. Theraulaz et al. (1998) gave the following helpful description of a (potential) stigmergic sequence:

"[] a stimulating configuration triggers a response, a building action, by a termite worker, transforming the configuration into another configuration that might trigger in turn another (possibly different) action performed by the same termite or any other worker in the colony."

We can see that stigmergic rules can provide start and termination points to the building activity: construction starts as a stimulating configuration or heterogeneity is found in the environment and ends when the last performed action leads to a non-stimulating configuration, causing all activity to stop without the need for external input. Also in this sense, stigmergy has been interpreted (Theraulaz et al. 1998; Camazine et al. 2001) as a form of indirect communication among workers, through modification of their environment (sematectonic communication; Wilson 1971), on the state of the ongoing construction.

However, stigmergic mechanisms do not necessarily result in behavioural coordination, even when workers are assumed to use the same rule set. In qualitative stigmergic building, unless all emerging configurations are unique, multiple stimulating configurations will become available at the same time, creating a landscape of multiple potential building states that are the result of the stochastic choices made by each worker at each step. In quantitative stigmergy, stochastic differences in the actions of individual workers will result in incoherence in the final structure that may put structure stability and efficiency (e.g., the thickness or evenness of a duct wall) at risk. How then might coherence be achieved?

\section{Self-assembly}

Some sets of qualitative stigmergic rules can guarantee structural coherence. Theraulaz and Bonabeau (1995); Bonabeau et al. (2000) explored the space of potential qualitative rule sets (building algorithms) identifying those that give rise to coordinated, coherent structures and called these sets coordinated algorithms. The resulting structures resemble nests built by social wasps. The authors identify at least one property common to all such rule sets: these algorithms produce only stimulating configurations that are non-overlapping, that is, that are unique to a single building stage, so that no more than one state can follow from a previous one (an emerging fixed sequence). The use of these rule sets by a group of builders leads to the creation of a geometrically complex and coherent structure, without the aid of other guiding mechanisms, and is termed self-assembly.

The coherence necessary to produce organised structures means that coordinated algorithms often create modularity. Similarly to what is observed in social wasp nests (Fig. 1a), the final structure consists of repeated, relatively less complex substructures in a semi-fixed arrangement. Moreover, these algorithms allow for variation in the final architecture (most commonly in the size and spatial organisation of substructures) arising from stochastic choices of individual builders when multiple stimulating configurations are active at any one step.

Interestingly, from an evolutionary perspective, these algorithms occupy a restricted and compact area of the space of all possible sets of rules. Similar rule sets give rise to similar architectures, so that mutations in one set can potentially switch the building to a neighbouring architecture in 
the configuration space (Theraulaz and Bonabeau 1995). Although Bonabeau and Theraulaz do not offer enough detail to understand the implications, it is possible that algorithms' rules are such that the use of two neighbouring rule sets within one group of builders can still result in a coherent final structure, because the similarity between the two sets implies that even the minority of rules that differ can be integrated without creating discontinuities. This possibility has important implications when considering mutations in building rules in an evolutionary scenario. Mutations carried by a sub-group of workers might be likely to shift rules to a neighbouring set, rather than a fully different one, and thus still produce a coherent structure when used jointly with the old set. Furthermore, the effect of random mutations can be overridden by an additional implication of coordinated rule sets: the type of configurations emerging during construction is partially or fully constrained, so that new rules are unlikely to ever be used (Theraulaz and Bonabeau 1995).

Although self-assembly seems to provide a sufficient explanatory mechanism for most architectural elements of composed wasp nests, architectures which are not obviously composed by the geometrical arrangement of building units and with higher complexity in their internal organisation can better be explained through self-organisation dynamics.

\section{Self-organisation}

Self-organisation is the process by which an organised pattern emerges from the quantitative interaction of behaviours (as opposed to the qualitative character of self-assembly). The key quantitative aspect involved here is the probability of performing a behaviour. In this sense, self-organisation is potentially cognitively cheaper than self-assembly: because the same rule can produce different intensities or frequencies of one behaviour and thus result in different outcomes at the collective level, fewer rules might be required and applicable at different construction stages, as long as the stimuli in each differ in the response triggered.

There are two main features that underlie self-organised dynamics:

1. The probabilistic, as opposed to deterministic, nature of the key behaviours is at the basis of most dynamics and of building initiation;

2. Feedback mechanisms often drive the spatial and temporal organisation of the behaviour.

Feedback mechanisms regulate the spatial and temporal coordination of workers by positively or negatively reinforcing a stimulus. Positive feedback directs the activity of an increasing number of workers towards the same location as others, thus co-localising effort. An example of a substructure emerging purely by self-organisation is the opening of lateral tunnels in Formosan subterranean termites (Bardunias and Su 2009b): because most unladen termites are travelling towards the excavation front, lateral tunnel branches tend to be initiated and develop in the direction away from the origin of the tunnel system. Stigmergic positive feedback driven by the incipient depression in the lateral wall then promotes the excavation of the tunnel in the right direction, while deposition, being independent from this stimulus, remains occurring at constant rate and prevents the closing of the main and developing tunnels by chance. Feedback can also provide an indirect means of optimising aspects of pattern efficiency linked to the feedback signal, as experimental evidence with ant foraging trail formation shows. In this case, foragers are drawn to a path by the increasing concentration of pheromone released by other ants. As this pheromone is volatile and falls below ants' response threshold after a few minutes, the path taken by the majority of ants over time will be the one for which passage frequency is highest, i.e., the shortest: time-related features of the signal optimise time efficiency in the pattern (Beckers et al. 1992a, b).

Initiation of building in self-organised systems is also often reliant on positive feedback: from random events triggered by probabilistic behaviour, a series of events close enough in time or space must occur to hit a stimulus threshold generating positive feedback (Theraulaz et al. 2003). For example, in termite and ant wall building, independent material collection and deposition by workers is often observed, but building is not initiated until a sufficient co-localised number of these events occur. Below a certain population size threshold, building is not initiated in termites, while increase in colony size below a certain proportion does not trigger wall expansion in T. albipennis nests (Franks and Deneubourg 1997). Initiation may also be guided by stigmergic rules or by other external stimuli that may carry adaptive information on the choice of building site or timing, as in Formosan subterranean termites, where depressions in the terrain also drive material pick up and deposition initiation (Bardunias and Su 2009b). In the ant Acromyrmex lundi, chamber construction and enlargement follow the relocation of brood (Römer and Roces 2014).

Convergence of the behaviour of the majority to a single state (e.g., one trail) driven by feedback occurs over time and passes through intermediate stages where a decreasing number of alternative states (e.g., the number of active trails) is active. This is driven by competition between positive feedbacks of nearby stimuli (two equally utilised paths), resulting in long-range reciprocal inhibition (after a distance threshold, both paths are equally attractive, while the chance of a new path forming in between is extremely low: negative feedback).

The switching point between states is reached when the intensity of the behaviour-triggering stimulus is great 
enough to become an attraction point over neighbouring stimuli. At points at which the switch is non-reversible, we have bifurcation points, where the system takes a turn towards the formation of what will become the final pattern. The direction taken at these points might be driven by external dynamics, such as the higher attraction force exercised by a better food source in decision making for foraging trails, or population dynamics intrinsic to the system, such as group size at different locations, and might allow for adjustment to external circumstances. Because of the stochastic component of behaviour, moreover, the same system might develop towards different final states according to the path taken at bifurcation points: multiple stationary states exist, allowing for variation in the range of final patterns observed. When the path taken is the result of stochastic fluctuations, the result is stochastic variation in the outcome.

Feedback-generating stimuli might be chemicals released by the workers, such as pheromones, but might also rely on indirect communication through stimulating stigmergic conformations (e.g., pick up at nest outlets, in Acromyrmex heyeri; Bollazzi \& Roces, 2010a), or even derive from spatial dynamics. T. albipennis nest wall building, for example, relies on the physical hindrance created by stone piles to ant movement, so that ants laden with sand are more likely to drop their pellet in the presence of stone heaps, ultimatelyin combination with a template_creating a wall (Franks and Deneubourg 1997).

Termination of the building activity is usually achieved through negative feedback by causes such as depletion of building material or by long-range inhibition dynamics.

In biological systems, the patterns emerging from selforganisation dynamics are often under fitness-driven selection. For this reason, in these systems, self-organisation dynamics nearly always interact with cues providing information on the neighbouring environment and on the effectiveness of the pattern, in a combined mechanism likely to have emerged under selection. These cues are the templates described above. In Acromyrmex heyeri, for example, the regulation of nest outlets opening and sealing is the result of the self-organisation of environmental template- and stigmergy-driven behaviour. The baseline pick-up rate of an ant worker is higher than its baseline deposition, maintaining the outlets open within the optimal range of environmental conditions. As the humidity of outflowing air increases, it acts as a template on deposition at the site, triggering an increase in its rate. Increasing deposition is counterbalanced by the stigmergic stimulus created by the growing heap of sand granules, which increases pick-up behaviour. The ratio of deposition to pick-up rate is what maintains the system in balance and prevents total closure of the outlets unless the escaping humidity is extremely high (Bollazzi and Roces 2010a)

\section{Consequences of self-organisation for complex nest building, adaptation and evolution}

\section{Transition between substructures emerges from environmental cues and local rules}

Self-organisation dynamics are likely to be at the basis of transitions between nest elements in the building of a nest, because they provide a simple mechanism for the creation of complex structures that does not require new behavioural rules. The emergence of distinct substructures can follow from the use of the same rule set consisting of few, simple building rules, that give rise to different shapes based just on the interaction with the physical or chemical properties of the environment where the behaviour is performed. For example, Bonabeau et al. (1998) present a computational model of Macrotermes subhyalinus galleries and chamber construction where the same diffusion principle that leads to wall formation from termite trails creates arch-shaped isoconcentrations of pheromonal template when termites walk on pillars or walls. Following this new gradient, building activity shifts from the production of pillars to that of gallery roofs. Similarly, the intersection of different trails generates a round-shaped inhibition effect due to high trail pheromone concentrations, leading to wider construction-free spaces: chambers.

Transition between substructures might also be modulated by the interaction of different templates, where neighbouring areas of the nest emerge from the interaction each of one distinct template. In this case, the shape of the area at the border between the two structures may be modelled by the quality and intensity of the interaction. In particular, we can envisage two scenarios (Fig. 3). Let us imagine two templates, template $A\left(T_{A}\right)$ and template $\mathrm{B}\left(\mathrm{T}_{\mathrm{B}}\right)$, with an overlapping area of influence $\mathrm{H}$ where both can be perceived by a worker at an intensity above its behavioural response threshold. In a scenario where $T_{A}$ and $T_{B}$ regulate the same behavioural rule, in the hybrid zone $\mathrm{H}$, the probability of performing the behaviour is either (1) determined by a combination of the two template effects or (2) controlled by the stronger template at that point in space. In case 1 , the effect on the behaviour within $\mathrm{H}$ will be higher than the effect of the behaviour within the one gradient area of either $\mathrm{T}_{\mathrm{A}}$ or $\mathrm{T}_{\mathrm{B}}$. The outcome will thus be an enhanced structural feature, such as a larger excavation area or thicker walls. In case 2 , where the stronger template at each spatial location dominates, simple merging of the two structures developing in opposite directions should be expected across $\mathrm{H}$.

In a scenario in which $\mathrm{T}_{\mathrm{A}}$ and $\mathrm{T}_{\mathrm{B}}$ modulate different behaviours, in contrast, the two behavioural mechanisms 


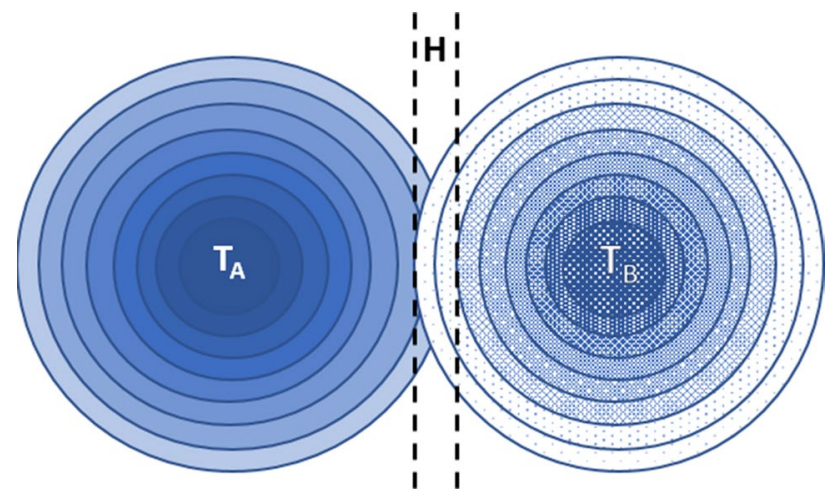

Fig. 3 Interaction of two building templates modulating the transition between neighbouring structures. Proximity between two templates $\left(\mathrm{T}_{\mathrm{A}}\right.$ and $\mathrm{T}_{\mathrm{B}}$ ) creates a hybrid zone $\mathrm{H}$ where their gradients overlap. The effect of $T_{A}$ and $T_{B}$ on behaviour, the relative intensity of each gradient in the hybrid zone and the compatibility between the two behavioural products determines what collective phenotype emerges in $\mathrm{H}$

will merge within $\mathrm{H}$. If they are compatible, an equilibrium structure that is the product of mechanism combination is reached, possibly generating new substructures. Conversely, if the competition between mechanisms cannot be resolved, this should be expected to result in an area of ongoing building activity, with builders removing material where deposition has just occurred.

Transition between substructures might alternatively be organised through stigmergic cues: qualitative stigmergy might trigger the shift between building behaviours as a stimulating conformation is reached and self-organisation might underlie the formation of such configurations. An example is the construction of the royal chamber by $M$. subhyalinus, which develops through shifts between substructures (Bruinsma 1979). Pillar construction around the queen shifts to expansion into lateral lamellae after a certain height is reached, followed by joining of lamellae into a roof and pillars merging into homogeneous walls. Here, the initiation of building activity is stimulated by the heterogeneities created by building material pellets scattered across the nest's floor.

It must be noticed that, from an evolutionary perspective and independently from the mechanism we consider, what we recognise as specialised substructures might have emerged by chance from the building dynamics initially evolved to meet different building needs. These new structures could then have been co-opted for specialised purposes, with scope for potential additional selection. As an example, we may imagine the hypothetical case of a ground-excavating termite species that exhibits faster digging behaviour in humid terrain, as in Coptotermes frenchi (Evans, 2003). During queue formation at the front of tunnel excavation, any lateral excavation (Bardunias and $\mathrm{Su}$ 2010) that meets an area of high humidity will lead to quick expansion of the new digging site and full exploration of the humid patch (Fig. 4, panels 1-4). As a consequence, chambers on the side of the main tunnel may emerge (Fig. 4, panel 5) that present the right humidity conditions to be later co-opted for other functions, such as hosting fungal symbionts. Overall, new experimental and modelling work is necessary to test these hypotheses.
1

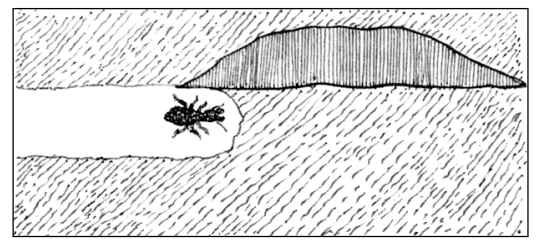

2

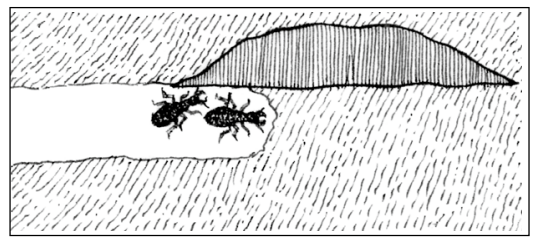

3

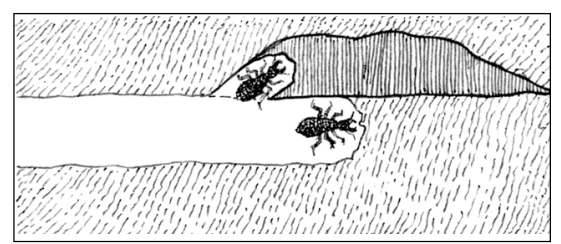

4

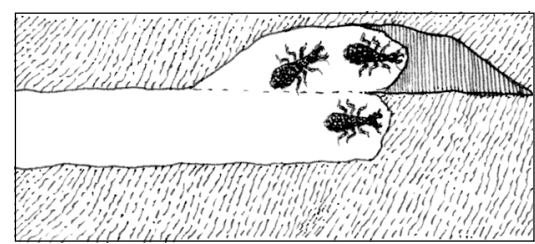

5

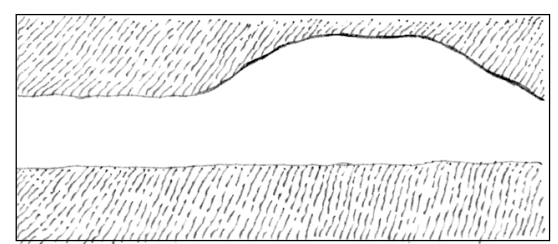

Fig. 4 Emergence of lateral chambers from tunnel digging dynamics. The figure shows the progression of events during tunnel building that could, in a hypothetical scenario, lead to the formation of high-humidity chambers, without rules specific to the formation of this chambers being required. The example illustrated is based on the behaviour displayed by Coptotermes frenchi and Formosan subterranean termites. Darker areas in the figure indicate zones of higher humidity in the digging substrate. Tunnel digging often leads to worker queue formation when the excavation front is occupied (1-2). Workers awaiting access have a constant probability of instead initiating lateral excavation along the queue (3). If excavation speed is higher in humid than dry terrain, as it is the case in Coptotermes frenchi, then lateral digging will proceed laterally until the whole humid patch is excavated, producing a lateral chamber (4-5) 


\section{Flexibility and the adaptiveness of nest structures}

The reliance of self-organisation on the convergence of probabilistic behaviours, or of inter-individual variation (Dussutour et al. 2009; Yamamoto and Hasegawa 2017), provides an additional advantage: flexibility. Beside the assessment of environmental cues that allow adaptation to the specific fixed characteristics of the local environment (i.e., average exposure to sun rays, direction of air currents, heterogeneities on terrain surface, etc.), the structure also dynamically responds to short-term changes, and to the colony (Turner 2007; Perna and Theraulaz 2017). Nest size, for example, is known to correlate to colony size (Tschinkel 2015), a phenomenon explained by the increase in building events and rate as the number of workers increases. Similarly, the intensity of worker activity provides a mechanism regulating structure size: the size of galleries increases in response to worker traffic rate.

These events in collective building are effectively a case of collective decision making. The competition between different possible cues of the same type (e.g., two air currents) attracting workers means that the colony is assessing multiple building alternatives at any one time. Probabilistic individual behaviour can be regarded as a means of exploration of the phenotypic landscape of the structure, with feedback dynamics ultimately creating convergence to one solution. Convergence will lead to the strongest template or the one with the most favourable spatial position (positive feedback driven by ease of access), if the difference in quality (the relative attraction basin) is large enough. It can, for example, be argued that the "winning" template emerging from the dynamics above can often coincide with an optimal decision for structure functionality (Beckers et al. 1992a, b; Franks et al. 2003; Sasaki et al. 2015). Recent studies suggest that these mechanisms can adapt flexibly to changes in the environment (Vittori et al. 2004; Reid et al. 2011; Ramsch et al. 2012; Latty and Beekman 2013; but see Beckers et al. 1992a, b), although the effectiveness of the change decreases if only a subset of individuals actively monitor cues (Sasaki et al. 2015). Fine-tuning feedback mechanisms to adjust the rate of increase as well as decrease in activity might be necessary for feedback dynamics to be triggered and efficient across colony sizes (Nicolis et al. 2003; Planqué et al. 2010; Latty and Beekman 2013). Often, self-organisation dynamics also need to account for trade-offs between different requirements of structure function (e.g., Perna et al. 2008a, b; Buhl et al. 2009; Bollazzi and Roces 2010b; Farji-Brener et al. 2015). Fine-tuning probabilistic behaviour could also be under evolutionary selective pressure for optimal exploitation in environments with different degrees of dynamicity (Deneubourg et al. 1983).

The response of structure shape to environmental conditions might not necessarily be adaptive. Rather, it might be a by-product of the physical properties of the environment (e.g., the higher digging speed of Coptotermes frenchi on wet in contrast to dry terrain might reflect a preference of the termites for humid environments, but it might also result from this type of terrain being easier to excavate; Evans 2003) or of rules that are adaptive in a different context (e.g., corpse pile formation in Messor sanctus is sensitive to wind speed, a response that is likely to have evolved for brood pick up and deposition preferences; Jost et al. 2007). Similarly, computer simulations have shown that many aspects of the shape of insect nests are likely the result of the interaction with physical properties of the terrain and other features in the environment, with templates contributing to the shaping of smaller structures only (Khuong et al. 2011; Ocko et al. 2019). Generally, while some self-organising mechanisms might have evolved under selection for architectural or behavioural optimisation, others might simply have emerged from the properties of cognitive networks or of physical and chemical laws and display features that, coincidentally, confer an evolutionary advantage: the case of Monomorium pharaonis foraging networks displaying a branching angle that confers optimal polarity to the network (Jackson et al. 2004; but see also, in Messor sanctus, Garnier, Combe, Jost, $\&$ Theraulaz, 2013), for example, is one of such non-clearcut cases.

\section{Robustness}

Feedback dynamics enable individuals to gather information about the level and location of the activity concomitantly performed by others. This concept has interesting implications in terms of mutations in building rules. Let us imagine a colony that responds to a template gradient with intensity $a$, so that building converges towards a point at distance $R_{a}$ from the template. Let us now imagine that a genetic mutation arises that changes the intensity of the response to the template to $b$, resulting in a preferred building distance $R_{b}$ from the template. What impact would this mutation have on construction? Most social insect species in which collective building occurs are eusocial, that is, with a particular colony genetic structure where the worker population is the offspring of one or a few breeding pairs, or of queens mated to one or few males. In these systems with high genetic similarity, genetic mutations can spread very quickly and create conflict among the building rules used by workers. In the presence of multiple genetic lines (polygynous colonies or multiply mated queen), workers abiding to different building rules are contributing to the same structure. Even when colonies are monogynous and the queen mated to a single male, dependent colony foundation or queen replacement means that a mutation carried by a member of the breeding pair spreads in the colony following worker turnover. In both scenarios, when a large enough proportion of workers responds 
to a template with the new variant $(b)$, the expected effect is structural incoherence, resulting in parts of the structure being built at different distances-or is it?

Where feedback mechanisms exist that guide individual activity based on collective activity, we might observe that the collective-level phenotype converges to an intermediate form between all variants of the building rule used. The exact shape of this intermediate phenotype depends on the relative influence of each variant on the intensity of positive and negative feedback that its product generates. The frequency at which variants are expressed and the discrepancy between their products are also likely to determine whether convergence can occur.

An illustration of how this process might unfold may be given using the example above (Fig. 5). Let us suppose that, in addition to a distance-from-a-template rule, the building product (sand deposited) also generates an attractive effect on workers, so that even more activity occurs in the presence of the product. Negative feedback dynamics that decrease the level of activity where the product is rarer also exist. At low frequency of variant $b$, the collective phenotype is likely to converge to variant $a$, because the $b$ product is rare (Fig. 5 , left side). When frequencies of $a$ and $b$ are similar, the two competing variants have areas of overlap in their template gradient. If there is a subarea of the overlap where the sum of the probability of deposition from both rules is higher than the single probabilities, then this is the area of highest attractiveness in the gradient. Group deposition converges towards this point and a collective phenotype intermediate between $a$ and $b$ emerges. The existence of such an area depends on the difference between $R_{a}$ and $R_{b}$ (the discrepancy between the variants) and on the shape of the gradient. A similar process can be envisaged in self-assembly when the new variant can be integrated with coherence with the existing rule set (i.e., the neighbouring coordinated algorithms described by Theraulaz and Bonabeau 1995).

A process of this type has important consequences for the evolutionary robustness of the building phenotype. It enables transition between changes in rule sets that are neutral to the adaptiveness of the structure when used by the collective (the nest survives the transition). It also lengthens the survival period of the nest when the mutation creates a non-adaptive architecture, as long as the mutation can be overridden at low frequency and the intermediate collective phenotype is adaptive. Furthermore, it has interesting implications for mutations in building rules that increase nest fitness. An adaptive mutation that allows, for example, a better match to a template by increasing sensitivity to it will also generate higher attractiveness, leading to adjustment of the group-level building phenotype before all workers in

\begin{tabular}{l|l|l|l|l|l|l}
\hline Colony events & $\begin{array}{l}\text { monogynous and } \\
\text { genetically } \\
\text { homogeneous } \\
\text { colony }(a)\end{array}$ & $\begin{array}{l}\text { Queen replacement: } \\
\text { new queen is } b \\
\text { carrier in its germline }\end{array}$ & worker turnover \\
\hline
\end{tabular}

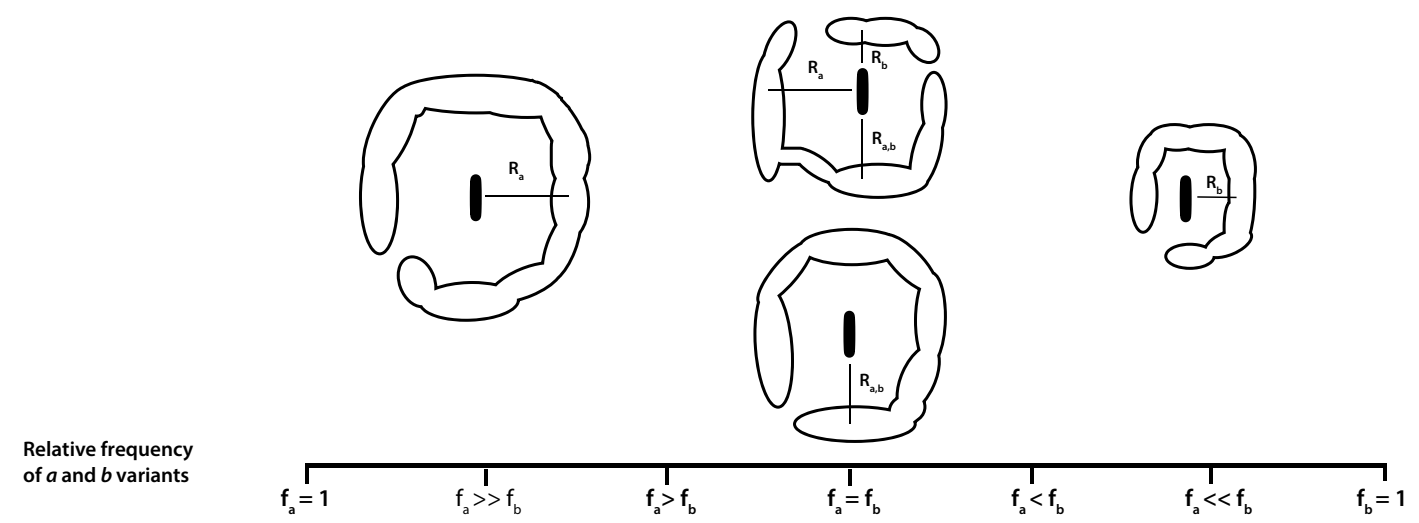

Fig. 5 Transition between building rules after genetic mutation in a monogynous colony. The figure shows change in the collective phenotype (centre) as the ratio between the frequencies of $a$ and $b$ variants of the building rule $R$ changes ( $x$ axis, bottom). Top: the corresponding events in the colony's life history are shown. The rule describes sensitivity to a template (black line in the centre of the structure) that creates a gradient of individual deposition and pickup probability as distance from the template increases. Deposition and pick-up probability increase and decrease, respectively, with distance from the template; the mechanism is identical to the model of royal chamber wall construction in termites (Bonabeau et al. 1998). From left to right: the colony is genetically homogeneous for rule $a$ and group deposition focuses at distance $R_{a}$ from the template (left). Queen replacement introduces variant $b$ in the worker population via mutation in the germline and the frequency of $b$ increases with worker turnover. When the frequency of $b$ starts approaching that of $a$, some wall sections will emerge at distance $R_{a}$, some at distance $R_{b}$ and some in areas of the overlap between gradients $a$ and $b$ where total deposition probability summed across both variants is high, $R_{a, b}$ (centre, top). Over time, collective activity will converge towards $R_{a, b}$ if this total probability is higher than individual probabilities at $R_{a}$ and $R_{b}$ (centre, bottom). The collective phenotype converges towards $R_{b}$ as $b$ workers become the predominant genotype in the colony. Image drawn by James Wilson 
the colony express the mutation. Conversely, adaptive rules that cannot influence feedback dynamics will be masked by other rules, until they reach high frequency among workers.

The scenarios described are of genetic mutation. However, the same principle means that these dynamics might enable individual variation in behaviour to be supported in a collective process. There is some indication that self-organising systems might be robust to individual error (Ramsch et al. 2012).

It is likely that minimising the impact of one disruptive mutation on the stability of the whole architecture remains an evolutionary problem. The full set of building rules used to generate a complete architecture needs to both minimise the total number of rules (parsimony) and to enable feedback between components, while maintaining as much independence as possible between rule subsets used in different structures. Separate ant nest features such as chamber shape, area, volume and spacing seem to evolve independently across the ant genus, pointing at a large degree of independence between the underlying rule sets (Tschinkel 2015).

\section{Conclusions}

The current literature on self-organisation and self-assembly in eusocial insect nest building provides in detail evidence and mechanistic description of how these mechanisms result in functional adaptation to environmental conditions. New studies are beginning to emerge that show how the response of the nest to the environment includes features that are an indirect response of dynamics and not functionally adaptive. We take these observations as a cue for discussing self-organisation from an evolutionary perspective. The emergence of even primitive forms of seemingly functionally fine-tuned nest substructures might be the by-product of other building dynamics, or might instead result from selective pressure to meet the structure's purpose. In this second case, theoretical studies of self-organisation should address the question of under which circumstances, premises and mechanisms can coordinated rule sets evolve. At the same time, self-organisation dynamics separate collective phenotype from the linear sum of individual phenotypes that govern baseline building activity, because individual variation in rules underlying feedback dynamics are a crucial element in determining the collective outcome. Therefore, the evolution of collective behaviour and of collective building in particular might display a pattern of phenotypic adaptation at the collective level that overrides individual-level mutations. Again, theoretical studies can enquire about the evolutionary trajectories followed by collective phenotypes under different eusocial structures, under drift and under adaptive selective pressures. Short-term adaptation to the immediate environment might occur through the exploration of collective phenotypic space mediated by convergence of individual choices to a collective decision. Experimental studies can investigate to which extent this parallel holds true. We invite new research, both experimental and theoretical, to approach self-organisation in collective building also from this evolutionary perspective.

Acknowledgements This work was funded by the John Templeton Foundation as part of the research collaboration grant "Putting the extended evolutionary synthesis to the test" (Grant no. 60501), as well as by the University of St Andrews. We thank the two reviewers and particularly Chris Reid for their helpful comments that considerably increased the quality of this review. Our thanks also go to Dr Takao Sasaki for letting us use his photographs of $T$. albipennis nests and to James Wilson for his beautiful drawing of termite tunnels.

\section{Compliance with ethical standards}

Conflict of interest The authors declare that they have no conflict of interest.

Open Access This article is distributed under the terms of the Creative Commons Attribution 4.0 International License (http://creativeco mmons.org/licenses/by/4.0/), which permits unrestricted use, distribution, and reproduction in any medium, provided you give appropriate credit to the original author(s) and the source, provide a link to the Creative Commons license, and indicate if changes were made.

\section{References}

Bardunias P, Su N-Y (2009a) Dead reckoning in tunnel propagation of the Formosan subterranean termite (Isoptera: Rhinotermitidae). Ann Entomol Soc Am 102(1):158-165. https://doi. org/10.1603/008.102.0118

Bardunias P, Su NY (2009b) Opposing headings of excavating and depositing termites facilitate branch formation in the Formosan subterranean termite. Anim Behav 78(3):755-759. https://doi. org/10.1016/j.anbehav.2009.06.024

Bardunias P, Su NY (2010) Queue size determines the width of tunnels in the formosan subterranean termite (Isoptera: Rhinotermitidae). J Insect Behav 23(3):189-204. https://doi.org/10.1007/ s10905-010-9206-Z

Beckers R, Deneubourg J-L, Goss S (1992a) Trails and U-turns in the selection of a path by the ant Lasius niger. J Theor Biol 159(4):397-415. https://doi.org/10.1016/S0022-5193(05)80686-1

Beckers R, Deneubourg JL, Goss S (1992b) Trail laying behaviour during food recruitment in the ant Lasius niger (L.). Insectes Soc 39(1):59-72. https://doi.org/10.1007/BF01240531

Bollazzi M, Roces F (2007) To build or not to build: circulating dry air organizes collective building for climate control in the leaf-cutting ant Acromyrmex ambiguus. Anim Behav 74(5):1349-1355. https ://doi.org/10.1016/j.anbehav.2007.02.021

Bollazzi M, Roces F (2010a) Control of nest water losses through building behavior in leaf-cutting ants (Acromyrmex heyeri). Insectes Soc 57(3):267-273. https://doi.org/10.1007/s0004 0-010-0081-6

Bollazzi M, Roces F (2010b) Leaf-cutting ant workers (Acromyrmex heyeri) trade off nest thermoregulation for humidity control. J Ethol 28(2):399-403. https://doi.org/10.1007/s10164-010-0207-3 
Bollazzi M, Forti LC, Roces F (2012) Ventilation of the giant nests of Atta leaf-cutting ants: does underground circulating air enter the fungus chambers? Insectes Soc 59(4):487-498. https://doi. org/10.1007/s00040-012-0243-9

Bonabeau E, Theraulaz G, Deneubourg JL, Franks NR, Rafelsberger O, Joly JL, Blanco S (1998) A model for the emergence of pillars, walls and royal chambers in termite nests. Philos Trans $\mathrm{R}$ Soc B Biol Sci 353(1375):1561-1576. https://doi.org/10.1098/ rstb.1998.0310

Bonabeau E, Guérin S, Snyers D, Kuntz P, Theraulaz G (2000) Three-dimensional architectures grown by simple "stigmergic" agents. Biosystems 56(1):13-32. https://doi.org/10.1016/S0303 -2647(00)00067-8

Bruinsma OH (1979) An analysis of building behaviour of the termite Macrotermes subhyalinus (Rambur). University of Wageningen, Wageningen

Buhl J, Hicks K, Miller ER, Persey S, Alinvi O, Sumpter DJT (2009) Shape and efficiency of wood ant foraging networks. Behav Ecol Sociobiol 63(3):451-460. https://doi.org/10.1007/s0026 5-008-0680-7

Camazine S, Deneubourg J-L, Franks NR, Sneyd J, Theraulaz G, Bonabeau E (2001) Self-organization in biological systems. Princeton University Press, Princeton

Ceusters R (1986) Simulation du nid naturel des fourmis par des ids artificiels placés sur un gradient de température. In Actes des Colloques Insectes Sociaux 3: 235-241

Coaton WGH, Sheasby JL (1972) Preliminary report on a survey of the termites (Isoptera) of South West Africa, vol 2. Cimbebasia memoir, Windhoek

Cosarinsky MI, Roces F (2012) The construction of turrets for nest ventilation in the grass-cutting ant Atta vollenweideri: import and assembly of building materials. J Insect Behav 25(3):222-241. https://doi.org/10.1007/s10905-011-9290-8

Darlington JPEC (1984) Two types of mound built by the termite Macrotermes subhyalinus in Kenya. Int J Trop Insect Sci 5(06):481492. https://doi.org/10.1017/S1742758400004914

Deneubourg J-L, Pasteels JM, Verhaeghe JC (1983) Probabilistic behaviour in ants: a strategy of errors? J Theor Biol 105(2):259271. https://doi.org/10.1016/S0022-5193(83)80007-1

DiRienzo N, Dornhaus A (2017) Temnothorax rugatulus ant colonies consistently vary in nest structure across time and context. PLoS One 12(6):e0177598. https://doi.org/10.1371/journal.pone.01775 98

Downing HA, Jeanne RL (1988) Nest construction by the paper wasp, Polistes: a test of stigmergy theory. Anim Behav 36(6):17291739. https://doi.org/10.1016/S0003-3472(88)80112-X

Dussutour A, Beekman M, Nicolis SC, Meyer B (2009) Noise improves collective decision-making by ants in dynamic environments. Proc R Soc B Biol Sci 276(1677):4353-4361. https://doi.org/10.1098/ rspb.2009.1235

Evans TA (2003) The influence of soil heterogeneity on exploratory tunnelling by the subterranean termite Coptotermes frenchi (Isoptera: Rhinotermitidae). Bull Entomol Res 93(05):413-423. https ://doi.org/10.1079/ber2003254

Farji-Brener AG, Chinchilla F, Umaña MN, Ocasio-Torres ME, Chauta-Mellizo A, Acosta-Rojas D, Amador-Vargas S (2015) Branching angles reflect a trade-off between reducing trail maintenance costs or travel distances in leaf-cutting ants. Ecology 96(2):510-517

Foelix RF (2011) Biology of spiders, 3rd edn. Oxford University Press, New York

Franks NR, Deneubourg JL (1997) Self-organizing nest construction in ants: individual worker behaviour and the nest's dynamics. Anim Behav 54(4):779-796. https://doi.org/10.1006/anbe.1996.0496

Franks NR, Wilby A, Silverman BW, Tofts C (1992) Self-organizing nest construction in ants: sophisticated building by blind bulldozing. Anim Behav 44(PART 2):357-375. https://doi. org/10.1016/0003-3472(92)90041-7

Franks NR, Dornhaus A, Fitzsimmons JP, Stevens M (2003) Speed versus accuracy in collective decision making. Proc R Soc B Biol Sci. https://doi.org/10.1098/rspb.2003.2527

Garnier S, Combe M, Jost C, Theraulaz G (2013) Do ants need to estimate the geometrical properties of trail bifurcations to find an efficient route? A swarm robotics test bed. PLoS Comput Biol. https://doi.org/10.1371/journal.pcbi.1002903

Grassé P-P (1939) La reconstrution du nid et le travail collectif chez les termites supérieurs. J Psych Norm Pathol 30:370-396

Grassé P-P (1959) La Reconstruction du nid et les coordinations interindividuelles chez Bellicositermes natalensis et Cubitermes Sp. La théorie de la stigmergie: Essai d'interprétation du comportement des termites constructeurs. Ins Soc 6:41. https://doi. org/10.1007/BF02223791

Grassé P-P, Noirot C (1961) Nouvelles recherches sur la systématique et l'éthologie des termites champignonnistes du genre Bellicositermes Emerson. Insectes Soc 8(4):311-359. https://doi. org/10.1007/BF02226554

Harris WV (1956) Termite mound building. Insectes Soc 3(2):261268. https://doi.org/10.1007/BF02224306

Höcherl N, Kennedy S, Tautz J (2016) Nest thermoregulation of the paper wasp Polistes dominula. J Therm Biol 60:171-179. https ://doi.org/10.1016/J.JTHERBIO.2016.07.012

Jackson DE, Holcombe M, Ratnieks FLW (2004) Trail geometry gives polarity to ant foraging networks. Nature 432(7019):907909. https://doi.org/10.1038/nature03105

Jost C, Verret J, Casellas E, Gautrais J, Challet M, Lluc J, Theraulaz G (2007) The interplay between a self-organized process and an environmental template: corpse clustering under the influence of air currents in ants. J R Soc Interface 4(12):107-116. https ://doi.org/10.1098/rsif.2006.0156

Khuong A, Theraulaz G, Jost C, Perna, Gautrais J (2011) A computational model of ant nest morphogenesis. In: Proceedings of the Eleventh European Conference on the Synthesis and Simulation of Living Systems (ECAL 2011), (January), 404-411. https:// doi.org/10.13140/2.1.1334.1122

King H, Ocko S, Mahadevan L (2015) Termite mounds harness diurnal temperature oscillations for ventilation. Proc Natl Acad Sci USA 112(37):11589-11593. https://doi.org/10.1073/pnas.14232 42112

Kleineidam C, Ernst R, Roces F (2001) Wind-induced ventilation of the giant nests of the leaf-cutting ant Atta vollenweideri. Naturwissenschaften 88(7):301-305. https://doi.org/10.1007/s001140100 235

Korb J, Linsenmair KE (1998) The effects of temperature on the architecture and distribution of Macrotermes bellicosus (Isoptera, Macrotermitinae) mounds in different habitats of a West African Guinea savanna. Insectes Soc 45(1):51-65. https://doi. org/10.1007/s000400050068

Latty T, Beekman M (2013) Keeping track of changes: the performance of ant colonies in dynamic environments. Anim Behav 85(3):637-643. https://doi.org/10.1016/J.ANBEHAV.2012.12.027

Lounibos LP (1975) The cocoon spinning behaviour of the chinese oak silkworm, Antheraea pernyi. Anim Behav 23:843-853. https://doi. org/10.1016/0003-3472(75)90109-8

Moreira A, Forti LC, Andrade AP, Boaretto MA, Lopes J (2004a) Nest Architecture of Atta laevigata (F. Smith, 1858) (Hymenoptera: Formicidae). Stud Neotrop Fauna Environ 39(2):109-116. https ://doi.org/10.1080/01650520412331333756

Moreira A, Forti LC, Boaretto MA, Andrade AP, Lopes J, Ramos VM (2004b) External and internal structure of Atta bisphaerica Forel (Hymenoptera: Formicidae) nests. J Appl Entomol 128(3):204211. https://doi.org/10.1111/j.1439-0418.2004.00839.x 
Nicolis SC, Detrain C, Animale B, Demolin D, Deneubourg JL (2003) Optimality of collective choices: a stochastic approach. Bull Math Biol 65:795-808. https://doi.org/10.1016/S0092-8240(03)00040 $-5$

Ocko SA, King H, Andreen D, Bardunias P, Turner JS, Soar R, Mahadevan L (2017) Solar-powered ventilation of African termite mounds. J Exp Biol 220(18):3260-3269. https://doi.org/10.1242/ jeb. 160895

Ocko SA, Heyde A, Mahadevan L (2019) Morphogenesis of termite mounds. Proc Natl Acad Sci 116(9):3379-3384. https://doi. org/10.1073/pnas.1818759116

Perna A, Theraulaz G (2017) When social behaviour is moulded in clay: on growth and form of social insect nests. J Exp Biol 220(1):83-91. https://doi.org/10.1242/jeb.143347

Perna A, Jost C, Couturier E, Valverde S, Douady S, Theraulaz G (2008a) The structure of gallery networks in the nests of termite Cubitermes spp. revealed by X-ray tomography. Naturwissenschaften 95(9):877-884. https://doi.org/10.1007/s0011 4-008-0388-6

Perna A, Valverde S, Gautrais J, Jost C, Solé R, Kuntz P, Theraulaz G (2008b) Topological efficiency in three-dimensional gallery networks of termite nests. Phys A 387(24):6235-6244. https://doi. org/10.1016/j.physa.2008.07.019

Planqué R, van den Berg JB, Franks NR (2010) Recruitment strategies and colony size in ants. PLoS One 5(8):e11664. https://doi. org/10.1371/journal.pone.0011664

Pomeroy DE (1977) The distribution and abundance of large termite mounds in Uganda. J Appl Ecol 14(2):465-475. https://doi. org/10.2307/2402559

Ramsch K, Reid CR, Beekman M, Middendorf M (2012) A mathematical model of foraging in a dynamic environment by trail-laying Argentine ants. J Theor Biol 306:32-45. https://doi.org/10.1016/j. jtbi.2012.04.003

Reid CR, Sumpter DJT, Beekman M (2011) Optimisation in a natural system: argentine ants solve the Towers of Hanoi. J Exp Biol 214(1):50-58. https://doi.org/10.1242/jeb.048173

Roces F, Kleineidam C (2000) Carbon dioxide concentrations and nest ventilation in nests of the leaf-cutting ant Atta vollenweideri. Insectes Soc 47(3):241-248. https://doi.org/10.1007/PL00001710

Römer D, Roces F (2014) Nest enlargement in leaf-cutting ants: relocated brood and fungus trigger the excavation of new chambers. PLoS One. https://doi.org/10.1371/journal.pone.0097872

Sasaki T, Colling B, Sonnenschein A, Boggess MM, Pratt SC (2015) Flexibility of collective decision making during house hunting in Temnothorax ants. Behav Ecol Sociobiol. https://doi.org/10.1007/ s00265-015-1882-4

Smith AP (1978) An investigation of the mechanisms underlying nest construction in the mud wasp Paralastor sp. (Hymenoptera: Eumenidae). Anim Behav 26:232-240. https://doi. org/10.1016/0003-3472(78)90023-4
Starr CK (1991) The nest as the locus of social life. In: Ross KJ, Matthews RW (eds) The social biology of wasps. Cornell University Press, New York, pp 525-529

Sudd JH (1972) The response of digging ants to gravity. Insectes Soc 19(3):243-250. https://doi.org/10.1007/BF02226629

Sumpter DST (2010) Collective animal behaviour. Princeton University Press, Princeton

Theraulaz G, Bonabeau E (1995) Modelling the collective building of complex architectures in social insects with lattice swarms. J Theor Biol 177(4):381-400. https://doi.org/10.1006/ jtbi. 1995.0255

Theraulaz G, Bonabeau E, Deneubourg J-L (1998) The origin of nest complexity in social insects learning from the models of nest construction. Complexity 3(6): 15-25

Theraulaz G, Gautrais J, Camazine S, Deneubourg J-L (2003) The formation of spatial patterns in social insects: from simple behaviours to complex structures. Philos Trans R Soc A Math Phys Eng Sci 361(1807):1263-1282. https://doi.org/10.1098/rsta.2003.1198

Thorpe W (1963) Learning and instinct in animals, 2nd edn. Methuen, London

Tohmé G (1972) Le nid et le comportement de construction de la fourmi Messor ebeninus, Forel (Hymenoptera, Formicoïdea). Insectes Soc 19(2):95-103. https://doi.org/10.1007/BF02224727

Tschinkel WR (2015) The architecture of subterranean ant nests: beauty and mystery underfoot. J Bioecon 17(3):271-291. https:// doi.org/10.1007/s10818-015-9203-6

Turner JS (2000) Architecture and morphogenesis in the mound of Macrotermes michaelseni (Sjöstedt) (Isoptera: Termitidae, Macrotermitinae) in northern Namibia. Cimbebasia 16:143-175

Turner JS (2001) On the mound of Macrotermes michaelseni as an organ of respiratory gas exchange. Physiol Biochem Zool 74(6):798-822. https://doi.org/10.1086/323990

Turner JS (2007) The tinkerer's accomplice : how design emerges from life itself. Harvard University Press, Cambridge

Verza SS, Forti LC, Lopes JFS, Hughes WOH (2007) Nest architecture of the leaf-cutting ant Acromyrmex rugosus rugosus. Insectes Soc 54(4):303-309. https://doi.org/10.1007/s00040-007-0943-8

Vittori K, Gautrais J, Araújo AFR, Fourcassié V, Theraulaz G (2004) Modeling ant behavior under a variable environment. In: International Workshop on Ant Colony Optimization and Swarm Intelligence, pp 190-201. Springer, Berlin, Heidelberg. https://doi. org/10.1007/978-3-540-28646-2_17

Wilson EO (1971) The insect societies. Belknap Press of Harvard University Press, Cambridge

Yamamoto T, Hasegawa E (2017) Response threshold variance as a basis of collective rationality. R Soc Open Sci 5:545. https://doi. org/10.1098/rsos.170097 